\title{
Biogas Generation Using Kitchen Waste
}

\author{
T Younas ${ }^{1, *}$, M Taha $^{2}$, S F Ehtesham ${ }^{2}$, M F Siddiqui ${ }^{2}$ \\ ${ }^{1}$ Assistant Professor, Department of Mechatronics Engineering, SZABIST, Karachi, Pakistan \\ ${ }^{2}$ Students, Department of Mechatronics Engineering, SZABIST, Karachi, Pakistan
}

\begin{abstract}
The previous years has been very crucial for the whole world so in Pakistan. This situation arise due to shocking increment in the rates of oil. In order to overcome this issue most of the countries are working for the development of technology using renewable resources. These resources include solar, wind and biomass. Biomass includes cow dung, kitchen waste, wood etc. The geographical location of Pakistan is a best suit for biomass energy operation. Among these biomasses this paper will be focusing on the kitchen waste which will result in around $60 \%$ of methane gas, $30 \%$ will include carbon dioxide, $8 \%$ nitrogen and rest 1 to $2 \%$ of hydrogen sulphide. This paper will state the best possible option to perform anaerobic digestion process in order to generate excess amount of biogas at homes. It will also discuss procedure for the removal of toxic gases which exist in biogas and can be harmful for humans as well as it degrade biogas quality. In our research, the generation of biogas and methane is done from the sugary and starch-rich material and is determined at small scale using the elementary digesters.
\end{abstract}

\section{Introduction}

Kitchen waste is bio-material having the high energy value and calorific value to microorganisms, that's why efficiency of biogas generation can be expanded by several ways of magnitude. The dumping of food waste is the main cause of pollution can be finished in low cost and environment friendly way [1] [2]. Considering cost effective is not the target the dumping of waste must be done in proper way for maintaining hygiene. The disposal of food in areas and making the places unhygienic and it needs the solution. Installation of biogas plants give the proper way of utilizing and proper storage of waste [3]. .The process of anaerobic digestion is a key path that allows to efficiently handle a use biofuel (which is comprised of mostly methane and one fourth of carbon dioxide) in order to produce energy [4].

There is a variation to attain the process of anaerobic digestion because the waste vary to produce energy as well the operating temperature. So production rate of biogas varies for each case [5].

Anaerobic Digestion is one of the method used to treat food waste. In rural areas the commonly used process is "anaerobic digestion of cow dung" but there are factors that limits the production and technical feasibility to continue the process [6]. Some of the factors affecting anaerobic digestion performance include physical structure of plants, the input to these plants and especially the operating temperature. The input feedstock includes size of particle, content of moisture, content of nutrient and biodegradability [7].

\section{Methods}

The step by step complete process is defined. Initially the collected kitchen waste is dumped into 4 litre shredder which consist of sharp blades which chopped the waste. The reason is to make process is smoother and less time consuming to generate a biogas. Once the significant amount of waste is gathered in digester tank, the process of anaerobic digestion starts [8]. The process is very precise we have to completely seal the digester. The digester have one inlet and four outlets. These inlet and outlets are connected with PVC pipes and valves. The input valve is connected to waste shredder, a valve placed at the bottom whose purpose is to remove the sludge. Above the sludge removal, fertilizer output valve is attached, this valve is used when level detector indicates that the digester has reached the set level. Meanwhile the input to digester tank is stopped and we reduce the matter through fertilizer outlet and then we can resume the process. This is a rich fertilizer and very good for the growth of plants.

The gas valves placed on top of digester, valve1 is connected to the purification filter while the valve 2 is for emergency if excess amount of gas is produced the emergency valve is connected to desulfurizer (filter) [9]. Valve 1 Connected to the purification filters to remove $\mathrm{CO}_{2}, \mathrm{CH}_{4}, \mathrm{H}_{2} \mathrm{~S}$ gas. The valvel is connected to three filters named as desulfurizer, $\mathrm{CO}_{2}$ scrubber and moisture remover. Desulfurizer contain a sponge of steel wool which removes $\mathrm{H}_{2} \mathrm{~S}$, then the gas is proceeded towards the $\mathrm{CO}_{2}$ scrubber which contains water to remove $\mathrm{CO}_{2}$ and finally to remove moisture we add moisture remover

\footnotetext{
*Corresponding author: tanzila@szabist.edu.pk
} 
filter which contain silica gel. After the three stages of filter purified biogas is stored further connected to stove. [10] [11]. The basic process diagram of biogas is shown in figure 1.

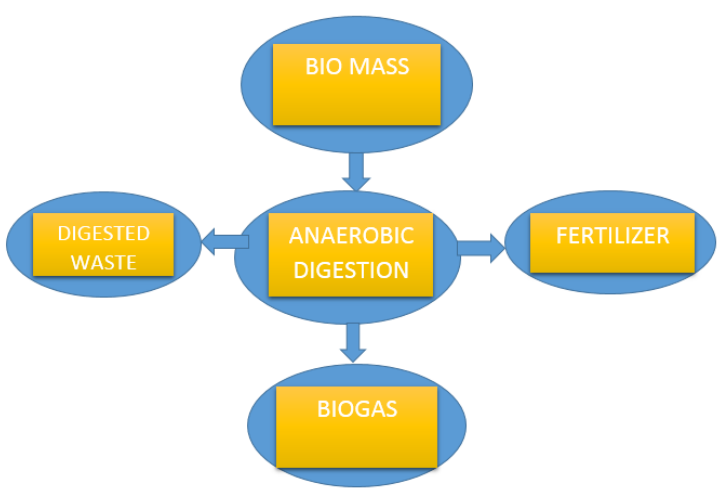

Figure 1. Complete process diagram.

\section{Discussion}

\subsection{Experimental Setup.}

The biogas plant is divided into four stages.

1. Waste Shredder

2. Digester Tank

3. Purification

4. Storage

\subsection{Parts involved in project.}

Following are the parts which are used in our project.

\subsubsection{Overall structure of the project.}

The structure for the portable biogas plant is of the dimension 6 by 4 feet. It is movable because it has 4 caster wheel joined to it. The biogas plant can be placed anywhere where the sunlight is accessible since it is portable. The dimensions of structure is shown in Table 1 . The structure is shown below in figure 2 .

Table 1. Structure dimension

\begin{tabular}{|l|l|l|}
\hline S.NO & Parameter & Size \\
\hline 01 & Length & 6 feet \\
\hline 02 & Breadth & 4 feet \\
\hline 03 & Height & 3 feet \\
\hline
\end{tabular}

\subsubsection{Digester dimension.}

It is the thick plastic drum as a digester chamber in which waste is added for anaerobic digestion process. The dimensions of digester is shown in Table 2. The digester is shown below in figure 3 .

\subsubsection{Waste shredder}

This drum is connected to a shredder which has a capacity of 4 liters and it contains two blades (saw tooth) for fine chopping. The dimensions of shredder is shown in Table 3. The shredder is shown below in figure 4 .

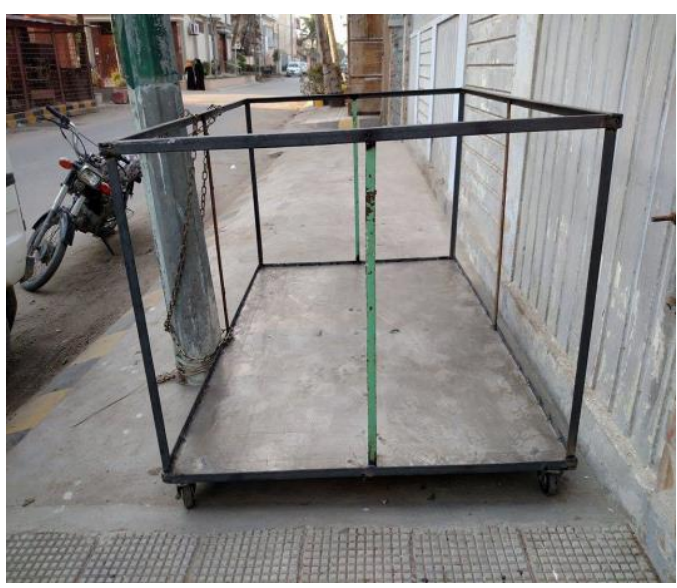

Figure 2. overall structure of project.

Table 2. Digester dimension

\begin{tabular}{|l|l|l|}
\hline S.NO & Parameter & Size \\
\hline 01 & Capacity & 208 litre \\
\hline 02 & Length & 2.91 feet \\
\hline 03 & Diameter & 2 feet \\
\hline
\end{tabular}

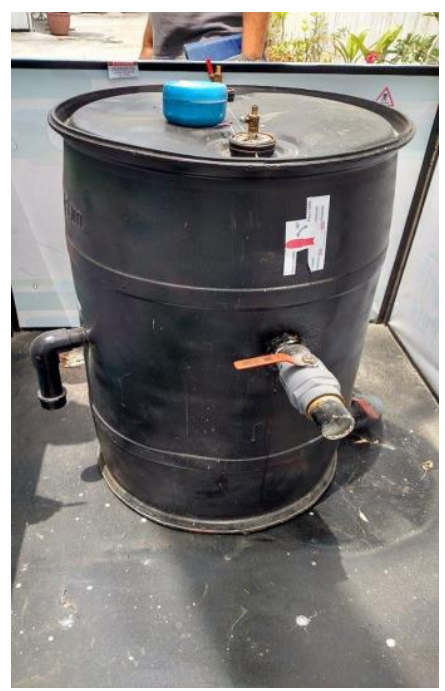

Figure 3. Biogas digester.

Table 3. Shredder dimension

\begin{tabular}{|l|l|l|}
\hline S. No. & Parameters & Size \\
\hline 01 & Capacity & 3 litre \\
\hline
\end{tabular}




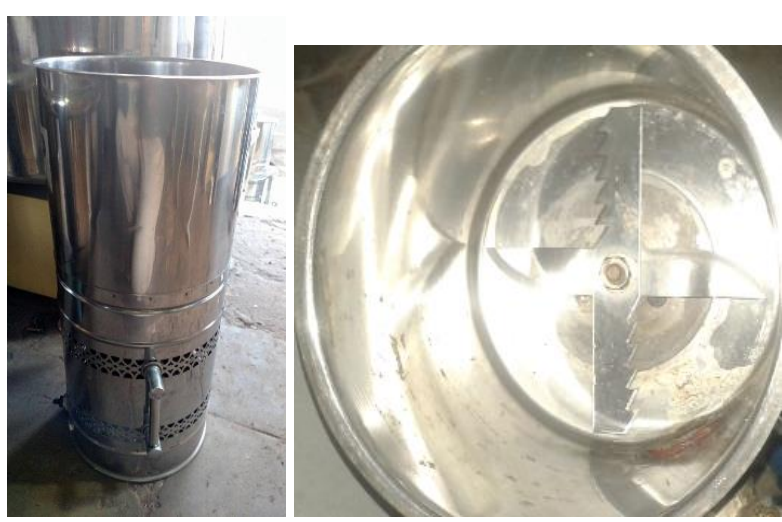

Figure 4. Waste shredder.

\subsubsection{Purification filters}

Then there are three filters biogas desulfurizer, biogas $\mathrm{CO}_{2}$ and biogas moisture remover which will be used for purification. The dimensions of filters is shown in Table 4. The filters is shown below in figure 5 .

Table 4. Filter dimension

\begin{tabular}{|l|l|l|}
\hline S.NO & Parameters & size \\
\hline 01 & Jerry can(biogas $\mathrm{CO}_{2}$ scrubber) & 20 litres \\
\hline 02 & biogas desulfurizer & 1.2 feet \\
\hline 03 & Biogas moisture remover & 0.9 feet \\
\hline
\end{tabular}

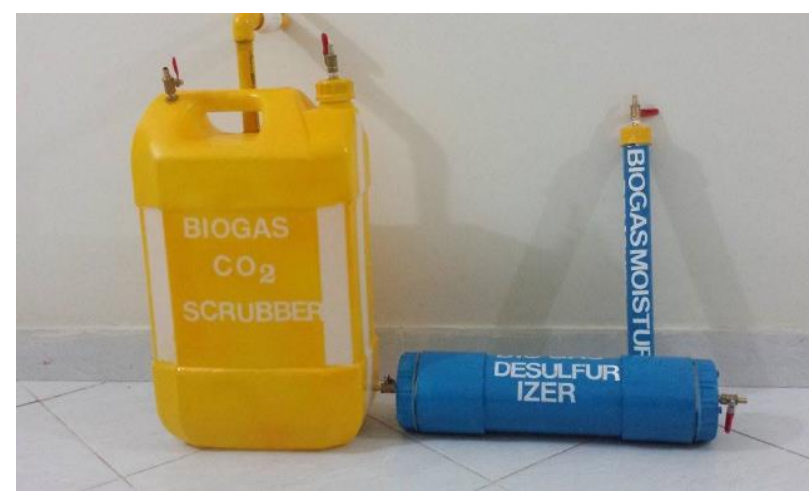

Figure 5. Purification filters.

\subsubsection{Biogas storage tube}

There is a tire tube is used as storage tank. The storage tube is shown below in figure 6 and tube dimensions is shown in table 5 .

Table 5. Storage tube dimension

\begin{tabular}{|l|l|l|}
\hline S. No. & Parameters & Size \\
\hline 01 & Tube diameter & 16 inch \\
\hline
\end{tabular}

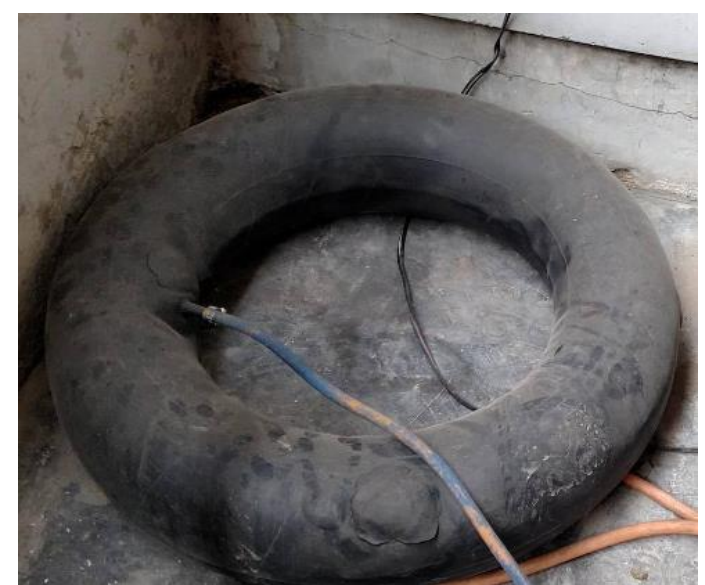

Figure 6. Storage tube.

\subsection{Electronics Part}

Following are the electronics components used in the project.

\subsubsection{Digester level detector}

Digester level detector consist of transistor, timer IC and the buzzer. The level detector is shown below in figure 7 .

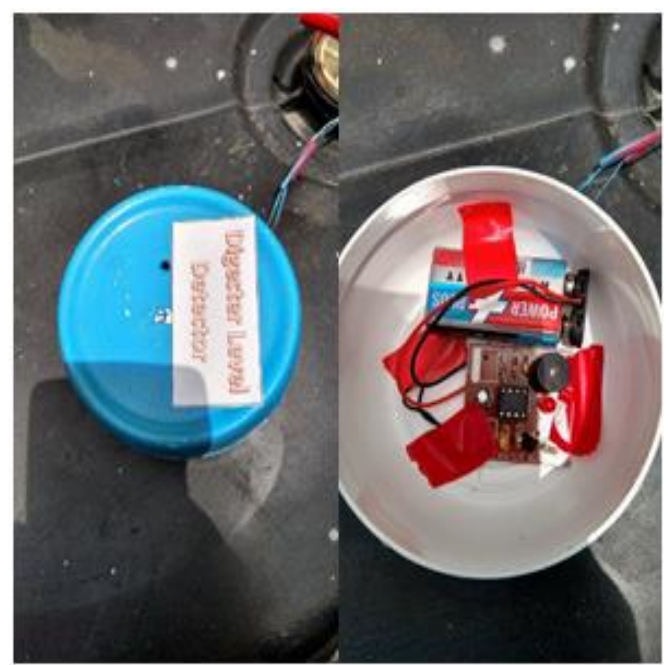

Figure 7. Digester level detector.

\subsubsection{Gas leakage detector}

Gas leakage detector consist of Arduino, gas sensor and indication circuit. The leakage detector is shown below in figure 8 .

\subsection{Working principle}

Organic matter prevail in form of biological material which is dead or living organisms. These organic substances usually compose of carbon and oxygen, sulphur hydrogen, nitrogen they combine to form many different such as proteins, lipids and carbohydrates. These microorganism break down by nature through digestion in smaller complex carbon substances. Anaerobic process is the digestion mechanism which 
happens without oxygen which generated different gases. By anaerobic mainly methane is produces which burns easily at room temperature and also it is eco-friendly which remove dependency on fossil fuels [12] [13].

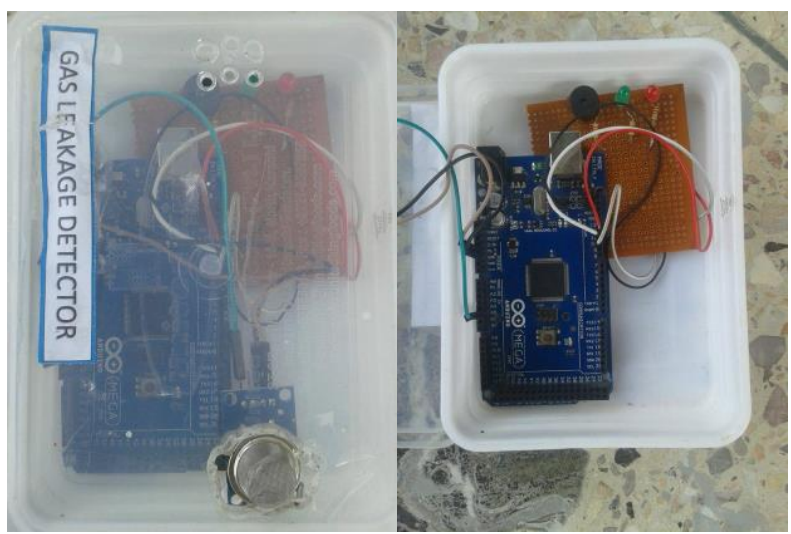

Figure 8. Gas leakage detector.

\section{Results}

For observation and analysis, we observe waste material and gas storage calculation need some basic values to calculate the results of experiments which are calculated below. The waste material is listed in Table 6

Table 6. Waste material

\begin{tabular}{|l|}
\hline Waste material \\
\hline Banana peel \\
\hline Carrots peel \\
\hline Okra \\
\hline Apple gourd \\
\hline Ridge \\
\hline Fenugreek \\
\hline Tomatoes \\
\hline Lettuce \\
\hline Egg plant \\
\hline Capsicum \\
\hline Arwi \\
\hline Potato \\
\hline
\end{tabular}

In this analysis in Table 7 we are observing change in diameter of tube in daily basis for checking gas generation. The result is shown in Table 7. A figure of biogas project can be shown in Figure 10.

Table 7. Result of tube diameter.

\begin{tabular}{|l|l|l|}
\hline S.NO & Days & Tube Diameter $($ Inch) \\
\hline 1 & 1 & 5 \\
\hline 2 & 2 & 8 \\
\hline 3 & 3 & 9 \\
\hline 4 & 4 & 12 \\
\hline 5 & 5 & 14 \\
\hline 6 & 6 & 16 \\
\hline 7 & 7 & 19.5 \\
\hline 8 & 8 & 20 \\
\hline
\end{tabular}

\begin{tabular}{|l|l|l|}
\hline 9 & 9 & 20 \\
\hline 10 & 10 & 21 \\
\hline 11 & 11 & 22 \\
\hline 12 & 12 & 23 \\
\hline
\end{tabular}

Figure 9, shows the graphical image of change in diameter of tube.

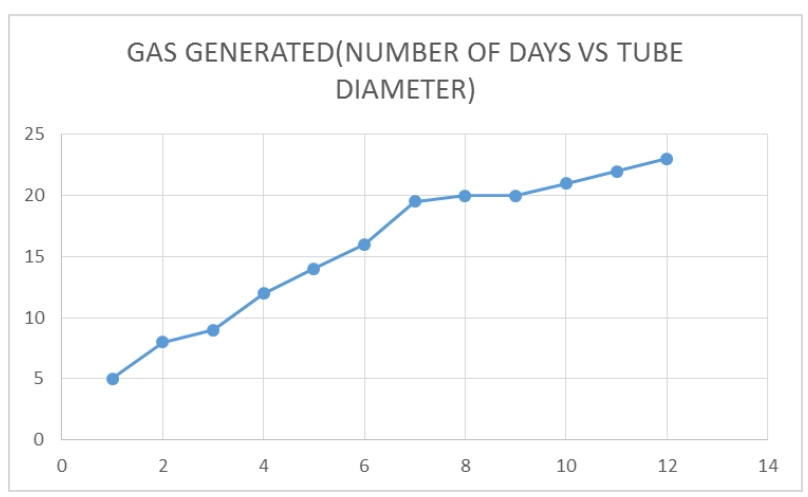

Figure 9. Graphical representation of gas generation.

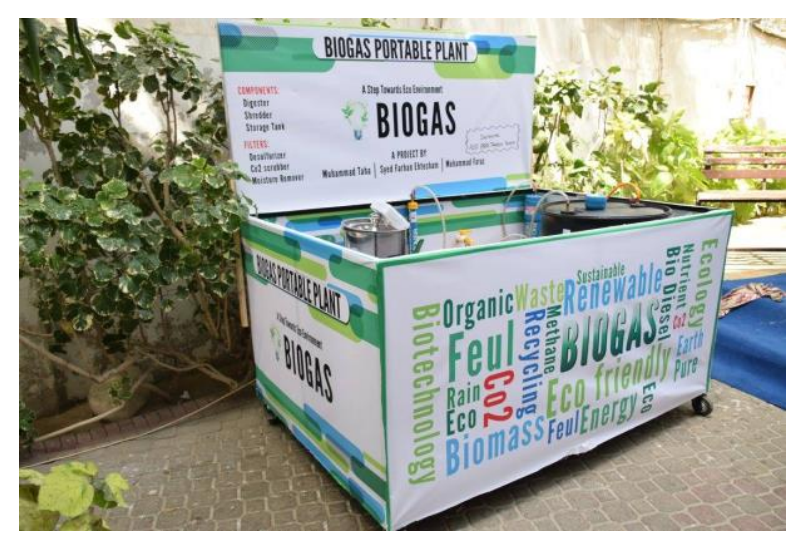

Figure 10. Biogas complete project.

\section{Conclusion}

The useful implementation of biogas portable plant for production of biogas by decomposing kitchen waste provide a solution of proper rigid waste management system. Its low price and it works independently and suitable considered parameters which show that it is economic. It is a technology that can be used for processing kitchen waste using a biogas digester .It has suddenly gained importance in the recent time and is a strong competitor in becoming the next renewable source of energy. This plant is more functional in urban areas as more amount of organic waste is produced in urban region because of larger population. Whereas it is value in rural regions because there is shortage of gas supply. In future it could decrease the dependency on $\mathrm{CNG}$ and LPG and thus future generations will not be depended on imported fossil fuel [14] [15] . 


\section{References}

1. D.Vikrant,P.Shekhar,"comparative study of biogas",International Journal of Engineering Science Invention, University of Pune, India, Vol2, 2013.

2. Q. Zhao, E. Leonhardt, C. MacConnell, C. Frear and S. Chen, "Purification Technologies for Biogas Generated by Anaerobic Digestion", CSANR Research Report 2010 - 001

3. Karve of Pune A.D "Compact biogas plant compact low-cost digester from waste starch". www.bioenergylists.org, (2006).

4. T.G.Jantsch, B.Matttiason, "An automated spectropphoyometric system for monitoring buffer capacity in anaerobic digestion processes"Water Research,Vol.38,p.3645- 3650,(2004).

5. D.Gloria Alagcan, S.K.Pratap, M.M.Alagcan, Ginasha, D.R, N.S.Tuivavalagi, S.K. Garg, "Use of Compact Biogas Plant for Biogas Production Utilizing Waste Food Materials, Fruits, and Vegetable Peelings of High Calorific Contents", International Journal of Engineering, ijesm Science and Metallurgy, Vol.2, 2012

6. A.C.Wilkie, "Biomethane from Biomass, Biowaste, and Biofuel", ASM Press, Washington DC,p.195205,2008

7. S.Chamarthi, S.C.Purnanand, V.Bhale, N.S.Reddy, C.C.Mouli, "Laboratory Scale Experiments for Biogas Production using Gas Chromatography Analysis", IOSR Journal of Engineering, Vol. 3,2013

8. V.Okudoh, "The potential of cassava biomass and applicable technologies for sustainable biogas production in South Africa", Renewable and Sustainable Energy, Vol 39, p.1035-1052,2014

9. P.Gauri Minde, S.Sandip, Magdum and V. Kalyanraman, "Biogas as a Sustainable Alternative for Current Energy Need of India", Journal of Sustainable Energy \& Environment, Vol 4, p.121132, 2013.
10. D.Gloria Alagcan, S.K.Pratap, M.M.Alagcan, Ginasha, D.R, N.S.Tuivavalagi, S.K. Garg, "Use of Compact Biogas Plant for Biogas Production Utilizing Waste Food Materials, Fruits, and Vegetable Peelings of High Calorific Contents", International Journal of Engineering, ijesm Science and Metallurgy, Vol.2, 2012.

11. H. Igoni, M. F. N. Abowei, M. J. Ayotamuno and C. L. Eze, "Effect of Total Solids Concentration of Municipal Solid Waste on the Biogas Produced In an Anaerobic Continuous Digester", 2008.

12. A.Ali, L.Rundong, "Predictive Modeling of Biogas Production from Anaerobic Digestion of Mixed Kitchen Waste at Mesophilic Temperature", International Journal of Waste Resources,2016

13. D.Gloria Alagcan, S.K.Pratap, M.M.Alagcan, Ginasha, D.R, N.S.Tuivavalagi, S.K. Garg, "Use of Compact Biogas Plant for Biogas Production Utilizing Waste Food Materials, Fruits, and Vegetable Peelings of High Calorific Contents", International Journal of Engineering, ijesm Science and Metallurgy, Vol.2, 2012

14. D.Gloria Alagcan, S.K.Pratap, M.M.Alagcan, Ginasha, D.R, N.S.Tuivavalagi, S.K. Garg, "Use of Compact Biogas Plant for Biogas Production Utilizing Waste Food Materials, Fruits, and Vegetable Peelings of High Calorific Contents", International Journal of Engineering, ijesm Science and Metallurgy, Vol.2, 2012

15. D.Gloria Alagcan, S.K.Pratap, M.M.Alagcan, Ginasha, D.R, N.S.Tuivavalagi, S.K. Garg, "Use of Compact Biogas Plant for Biogas Production Utilizing Waste Food Materials, Fruits, and Vegetable Peelings of High Calorific Contents", International Journal of Engineering, ijesm Science and Metallurgy, Vol.2, 2012 